AMERTANACADEMY OF AMERICAN ACADEMY OF
NEUROLOGY。

Gould, MD, PhD

Wayne E. Anderson, DO

Melissa J. Armstrong,

$\mathrm{MD}, \mathrm{MSc}$

Adam B. Cohen, MD

Matthew A. Eccher, MD, $\mathrm{MSPH}$

Donald J. Iverson, MD,

FAAN

Sonja B. Potrebic, MD,

$\mathrm{PhD}$

Amanda Becker

Rod Larson

Alicia Gedan

Thomas S.D. Getchius

Gary S. Gronseth, MD, FAAN

Correspondence to

American Academy of Neurology: tgetchius@aan.com

Editorial, page 946

See page 1022

Supplemental data at www.neurology.org

\section{The American Academy of Neurology's Top Five Choosing Wisely recommendations}

(6)

\section{ABSTRACT}

Objective: To discuss the American Academy of Neurology (AAN)'s Top Five Recommendations in the Choosing Wisely campaign promoting high-value neurologic medicine and physician-patient communication. The AAN published its Top Five Recommendations in February 2013 in collaboration with the American Board of Internal Medicine Foundation and Consumer Reports.

Methods: A Choosing Wisely Working Group of 10 AAN members was formed to oversee the process and craft the evidence-based recommendations. AAN members were solicited for recommendations, the recommendations were sent out for external review, and the Working Group members (article authors) used a modified Delphi process to select their Top Five Recommendations.

Results and recommendations: The Working Group submitted 5 neurologic recommendations to the AAN Practice Committee and Board of Directors; all 5 were approved by both entities in September 2012. Recommendation 1: Don't perform EEGs for headaches. Recommendation 2: Don't perform imaging of the carotid arteries for simple syncope without other neurologic symptoms. Recommendation 3: Don't use opioids or butalbital for treatment of migraine, except as a last resort. Recommendation 4: Don't prescribe interferon- $\beta$ or glatiramer acetate to patients with disability from progressive, nonrelapsing forms of multiple sclerosis. Recommendation 5: Don't recommend carotid endarterectomy for asymptomatic carotid stenosis unless the complication rate is low $(<3 \%)$. Neurology ${ }^{\circledR} 2013 ; 81: 1004-1011$

\section{GLOSSARY}

AAN = American Academy of Neurology; ABIMF = American Board of Internal Medicine Foundation; CEA = carotid endarterectomy; $\mathbf{G D P}=$ gross domestic product; $\mathbf{M S}=$ multiple sclerosis; $\mathbf{P P M S}=$ primary progressive multiple sclerosis; $\mathbf{R R M S}=$ relapsing-remitting multiple sclerosis; SPMS = secondary progressive multiple sclerosis.

Alzheimer disease, Parkinson disease, stroke, and multiple sclerosis affect approximately 15 million people and account for more than $\$ 290$ billion in health care spending annually in the United States. ${ }^{1,2}$ The number of people with these neurologic disorders is expected to increase, ${ }^{1,3}$ likely resulting in increased health care spending.

Each year, US health care spending increases, putting additional pressure on the national economy and individual consumers. According to estimates from the Centers for Medicare \& Medicaid Services, the United States spent $\$ 2.7$ trillion (17.9\% of the gross domestic product [GDP]) on health care in 2011. ${ }^{4}$ If the growth of health care expenditures is not curtailed, health care spending is projected to constitute $25 \%$ of the GDP by 2025,5 according to the Congressional Budget Office. The Institute of Medicine estimates that $\$ 750$ billion was spent on wasted medical services, including unnecessary services, inefficiently delivered services, and missed prevention opportunities, ${ }^{6}$ in 2009 alone. The rising cost of health care and wasteful spending often affect the consumer directly through increased deductibles and copayments and indirectly through deductions from wages or lost wage increases. $^{7}$

\footnotetext{
From the Neurology Department, Los Angeles Medical Center (A.M.L.-G.), Southern California Kaiser Permanente Medical Group (S.B.P.), Los Angeles; Department of Research \& Evaluation (A.M.L.-G.), Kaiser Permanente Southern California, Pasadena; California Pacific Neurosciences Institute (W.E.A.), San Francisco; Department of Neurology (M.J.A.), University of Maryland School of Medicine, Baltimore; Massachusetts General Hospital (A.B.C.), Harvard Medical School, Cambridge; Geisinger Medical Center (M.A.E.), Danville, PA; Humboldt Neurological Medical Group, Inc. (D.J.I.), Eureka, CA; American Academy of Neurology (A.B., R.L., A.G., T.G.), Minneapolis, MN; and University of Kansas Medical Center (G.S.G.), Kansas City.

Go to Neurology.org for full disclosures. Funding information and disclosures deemed relevant by the authors, if any, are provided at the end of the article.
} 
In response to wasteful practices, the American Board of Internal Medicine Foundation (ABIMF), in a joint partnership with Consumer Reports, has initiated a campaign to create a sincere, ongoing dialogue between physicians and patients. The campaign, Choosing Wisely, encourages medical specialty societies to develop lists of "Top Five Recommendations" detailing 5 procedures or examinations in their specialty that are overused or misused and may contribute to health care waste.

The American Academy of Neurology (AAN) joined the campaign in the second cohort, along with 15 other medical specialty societies. The AAN's Top Five Recommendations are intended to help patients choose care that is supported by evidence of benefit and avoid non-evidencebased practices that lead to harm or are driven primarily by reimbursement incentives rather than medical necessity. The Top Five Recommendations are not intended to eliminate use of these procedures or tests entirely but rather to give patients and physicians full information to engage in an honest discussion about when and in whom these medications, tests, or procedures may be more harmful than beneficial or simply unnecessary.

METHODS The ABIMF allowed all participating medical specialty societies to create their Top Five lists independently, with a few guidelines for selection (table 1). ${ }^{8}$ The AAN Practice Committee Chair selected 10 AAN members with experience in evidence-based medicine and practice guideline development from various neurologic subspecialties (general neurology, vascular neurology, movement disorders, headache, epilepsy, multiple sclerosis, and neuromuscular) and various practice settings (private practice, academic practice, and integrated managed care organizations) to serve on the Choosing Wisely Working Group along with 4 AAN staff.

After initial meetings were held to discuss the process (figure 1), an article outlining the AAN's involvement was included in AANe-News, a twice-monthly e-newsletter sent to all AAN members. The AAN then sent an email to all US members inviting them to submit their recommendations for consideration for the Top 5 list through the AAN Web site. In total, 178 neurology-related submissions were received in the 2-week time period.

Working Group members used an e-Consensus, modified Delphi process, mirroring the AAN's guideline development process, to rank nominated recommendations by their judged potential benefit and harm. ${ }^{9}$ Based on this ranking and additional discussion, the Working Group selected 11 finalist recommendations (table 2).

Working Group members subsequently developed rationales with supporting evidence for each finalist recommendation. Working Group members then evaluated each recommendation and its rationale for adherence to the domains listed in figure e-1 on the Neurology ${ }^{\circledR}$ Web site at www.neurology.org. ${ }^{9}$ At this stage, 4 candidate recommendations were eliminated because fewer than $80 \%$ of Working Group members judged the supporting rationales to be strongly cogent.

The Working Group sent the remaining 7 candidate recommendations to relevant AAN sections and committees, specialty societies, and patient advocacy organizations for review. Subsequently, the Working Group authors incorporated changes from the external review into the recommendations. Finally, the Working Group reviewed the recommendations in final format and anonymously voted to establish the AAN's Top Five Choosing Wisely recommendations.

The initial voting process produced 5 recommendations, 4 dealing with headache-related issues, 2 of which were redundant with existing recommendations from the first Choosing Wisely campaign. The Working Group, in consultation with the AAN Board of Directors, decided to vote a second time in an effort to diversify the range of neurologic issues in the recommendations to reflect the multiple diseases and disorders treated by neurologists. The Working Group anonymously voted a second time, and the vote yielded a more diversified field of neurologic recommendations by adding the sixth and seventh recommendations from the e-Consensus process. The headache recommendations not selected will be considered as recommendations for future Choosing Wisely lists. When the recommendations were approved and finalized by the Working Group, the Top Five list was sent to the AAN Practice Committee for approval and then to the AAN Board of Directors. Both the Practice Committee and the Board of Directors carefully reviewed the recommendations and voted to approve the AAN's Top Five Choosing Wisely recommendations (table 3).

Choosing Wisely's first cohort of medical specialty societies used methods similar to the AAN's process for selecting its Top Five Recommendations. Almost every society that provided a methodology explanation cites the use of either a Working Group or a Task Force charged with overseeing the Choosing Wisely process within the society. These Working Groups usually contained members from society committees on public policy, clinical practice, and quality. About half of the first cohort of societies generated ideas for recommendations from within the Working Group while the other half solicited ideas from their membership. Societies that solicited ideas from their membership received fewer than 100 recommendation submissions; the AAN's 178 submissions should thus be considered above average.

\section{RESULTS AND RECOMMENDATIONS Recommendation:} Don't perform EEGs for headaches. Headache is the most common pain disorder. Episodic migraine is as common as asthma and diabetes. ${ }^{10}$ As part of the diagnostic evaluation, EEGs are sometimes performed in patients with

\section{Table 1 American Board of Internal Medicine Foundation Top Five selection criteria}

1. The service is commonly performed

2. There is strong evidence that demonstrates the service offers no benefit to most patients or is in fact often harmful

3. The service, in aggregate, is expensive

4. Shifting to another option, or eliminating the service entirely, is within the control of the individual physicians (within the specialty's purview and control) 
Figure $1 \quad$ AAN Choosing Wisely process flow chart

The AAN agreed to participate in Phase II of ABIMF's Choosing Wisely campaign (May 2012)

The AAN Practice Committee Chair selected members from the Practice Committee and its subcommittees to serve on the Working Group (May 2012)

The AAN included a story in AANe-News about its involvement in Choosing Wisely; email sent to AAN members soliciting ideas for neurology-related recommendations. A total of 178 ideas submitted on aan.com over the course of 2 weeks (June 2012)

The Working Group reviewed and anonymously ranked all of the submissions in terms of judged harms and benefits; the Working Group selected 11 finalist recommendations from the 178 submitted (July 2012)

Each member of the Working Group selected at least one recommendation and performed a pragmatic systematic literature review; following the literature review, the Working Group members authored evidence-based rationales for the recommendations (end of July 2012)

All of the recommendations with rationales were reviewed by the Working Group and voted on anonymously for adherence to the domains enumerated in the 2011 AAN Clinical

Practice Guideline Process Manual. Four recommendations with less than $80 \%$ agreement were eliminated, leaving 7 recommendations for further review by the Working Group

(August 2012)

Requests for external feedback were sent out to relevant AAN sections, committees, medical specialty societies, and patient advocacy groups; comments were reviewed and incorporated into the recommendations by the Working Group (mid-August 2012)

Following a review of all 7 revised recommendations, the Working Group voted anonymously on the 7 recommendations to select a "Top Five" (mid-August 2012)

In consultation with the AAN Board of Directors, the Working Group decided to vote a second time due to a lack of neurologic diversity (four of five recommendations involved headache) in the initial "Top Five" recommendation list. The Working Group voted to drop two of the headache recommendations and added the sixth and seventh recommendations from the e-Consensus process (September 2012)

The AAN Board of Directors voted to approve the revised "Top Five" recommendation list for submission to Choosing Wisely (September 2012)

AAN $=$ American Academy of Neurology; ABIMF = American Board of Internal Medicine Foundation.

headache. Patients with clinically diagnosed migraine have high-frequency photic driving responses on EEG (the $\mathrm{H}$ response) when compared with people without headaches or patients meeting clinical criteria for nonmigraine headache disorders. ${ }^{11}$ Photic stimulation on routine EEGs is not typically performed at the high frequencies (30 to $40 \mathrm{~Hz}$ ) necessary to identify an $\mathrm{H}$ response. In addition, the presence of an $\mathrm{H}$ response has no advantage over the clinical reference standard in diagnosing headache disorders. A few patients with headaches have features (e.g., abnormal neurologic examinations) that suggest the presence of a structural cause such as a mass lesion. ${ }^{12}$ Such patients need 
1. Don't perform imaging of the carotid arteries for simple faints

2. Don't perform EEGs for headaches

3. Don't perform epidural steroid injections to treat nonradicular low back pain

4. Don't perform brain imaging studies for patients with a recurrent episode of a baseline primary headache disorder upon presentation to the emergency department

5. Don't perform imaging of the brain for nonacute primary headache disorders

6. Don't prescribe interferon- $\beta$ or glatiramer acetate to patients with disability from progressive forms of multiple sclerosis who have not had a relapse within the past 3 years

7. Don't use opioids or butalbital for treatment of migraine, except in rare circumstances

8. Don't recommend lumbar fusion surgery for low back pain

9. Don't recommend surgery for a narrowed carotid artery that has not caused symptoms unless the surgeon or proceduralist has a documented complication rate of less than $3 \%$

10. Don't perform neuroimaging of a postictal patient with known recurring seizures if the patient is returning to neurologic baseline in his or her customary time course for doing so

11. Don't perform EMGs for back pain without symptoms or signs of radiculopathy

additional diagnostic tests to exclude a more serious cause of headache. The sensitivity of the EEG to these structural causes of headache is considerably less than that of neuroimaging with CT or MRI. ${ }^{12}$ Therefore, performing EEGs in patients with headache increases cost without adding benefit. A normal EEG in a patient with headache with features suggesting the presence of a structural abnormality may provide a false sense of security and delay performance of definitive neuroimaging. In addition, the presence of incidental EEG abnormalities (e.g., mild focal slowing or questionable epileptiform activity) in a patient with a primary headache disorder may prompt use of additional unnecessary procedures or treatments.

Recommendation: Don't perform imaging of the carotid arteries for simple syncope without other neurologic symptoms. Syncope is common, with a lifetime prevalence of $40 \% .{ }^{13}$ Carotid imaging studies such as carotid duplex are commonly performed in patients presenting with syncope. ${ }^{14}$ When symptomatic, occlusive carotid artery disease causes focal neurologic symptoms and not syncope. ${ }^{15}$ In addition, studies demonstrate that even elderly patients with syncope are unlikely to have carotid occlusive disease. ${ }^{16}$ Therefore, performing carotid imaging studies in patients with syncope increases cost without adding benefit. Furthermore, carotid imaging may identify incidental asymptomatic occlusive carotid artery disease that may be inappropriately assumed to be the cause of the syncope. This can delay the identification of the true cause of syncope and may subject the patient to additional risk-associated procedures such as catheter angiography, carotid endarterectomy (CEA), or carotid stenting.

Recommendation: Don't use opioids or butalbital for treatment of migraine, except as a last resort. Migraine is the most frequent cause of headache seen in the medical office, urgent care, or emergency department. Almost all patients should receive migraine-specific medications or nonopioid, nonbarbiturate analgesics because these medications are the most effective migraine treatments. ${ }^{12,17-21}$ However, many patients continue to receive opioids or butalbital for migraine treatment. Use of opioids and butalbital increases the risk of medication overuse headache and chronic migraine. ${ }^{22}$ The per capita cost of medication overuse headache and chronic migraine is 3 times that of episodic migraine. ${ }^{23,24}$ When medical conditions such as cardiovascular disease or pregnancy preclude use of migraine-specific treatments, or when migraine-specific treatments fail, opioids are sometimes considered for rescue therapy. In these circumstances, use should be limited to 9 days per month or less to avoid medication overuse headache, and providers should continue to focus on preventive and behavioral aspects of migraine care. In addition, long-term follow-up is needed to prevent treatment complications.

Recommendation: Don't prescribe interferon $\boldsymbol{\beta}$ or glatiramer acetate to patients with disability from progressive, nonrelapsing forms of multiple sclerosis. Interferon- $\beta$ and glatiramer acetate reduce relapse rates in patients with relapsing-remitting multiple sclerosis (RRMS) without significant disability at the time treatments are initiated. ${ }^{25-27}$ Interferon- $\beta$ has also been shown to slow short-term, relapse-related disability progression in this population. ${ }^{25,26}$ However, when disability is established in patients with secondary progressive MS (SPMS) or primary progressive MS (PPMS), interferon- $\beta$ does not prevent the development of further, permanent disability. ${ }^{28,29}$ Interferon- $\beta$ has been shown to reduce the risk of relapse and short-term, relapserelated disability from SPMS ${ }^{30}$ and therefore may be appropriate in patients with continued relapse activity. 


\section{Don't perform EEGs for headaches.}

EEG has no advantage over clinical evaluation in diagnosing headache. Recurrent headache is the most common pain problem, affecting $15 \%$ to $20 \%$ of people. Source: Gronseth GS, Greenberg MK. The utility of the electroencephalogram in the evaluation of patients presenting with headache: a review of the literature. Neurology 1995;45:1263-1267.

\section{Don't perform imaging of the carotid arteries for simple syncope without other neurologic symptoms.}

Occlusive carotid artery disease does not cause fainting but rather causes focal neurologic deficits such as unilateral weakness. Fainting is a frequent symptom, affecting $40 \%$ of people during their lifetime.

Sources: Strickberger SA, Benson DW, Biaggioni I, et al.; American Heart Association Councils on Clinical Cardiology, Cardiovascular Nursing, Cardiovascular Disease in the Young, and Stroke; Quality of Care and Outcomes Research Interdisciplinary Working Group; American College of Cardiology Foundation; Heart Rhythm Society; American Autonomic Society. AHA/ACCF Scientific Statement on the evaluation of syncope. Circulation 2006;113:316-327.

Moya A, Sutton R, Ammirati F, et al.; Task Force for the Diagnosis and Management of Syncope; European Society of Cardiology (ESC); European Heart Rhythm Association (EHRA); Heart Failure Association (HFA); Heart Rhythm Society (HRS). Guidelines for the diagnosis and management of syncope (version 2009). Eur Heart J 2009;30:2631-2671.

Rogers G, O'Flynn N. NICE guideline: transient loss of consciousness (blackouts) in adults and young people. Br J Gen Pract 2011;61:40-42.

3. Don't use opioids or butalbital for treatment of migraine, except as a last resort.

Opioid and butalbital treatment for migraine should be avoided because more effective, migraine-specific treatments are available. Opioids and butalbital are associated with medication overuse headache. Opioids should be reserved for those with medical conditions precluding use of migraine-specific treatments or for those who fail these treatments. These medications should be used 9 days a month or less. In addition, preventive treatments and attention to lifestyle factors are an important part of migraine care.

Sources: Silberstein SD. Practice parameter: evidence-based guidelines for migraine headache (an evidence-based review): report of the Quality Standards Subcommittee of the American Academy of Neurology. Neurology 2000;55:754-762.

Evers S, Afra J, Frese A, et al.; European Federation of Neurological Societies. EFNS guideline on the drug treatment of migraine: revised report of an EFNS task force. Eur J Neurol 2009;16:968-981.

Institute for Clinical Systems Improvement. Health care guideline: diagnosis and treatment of headache, 10 th edition. Published January 2011. Available at: https:// www.icsi.org/_asset/jhzzv6/Headache-Interactive0111.pdf. Accessed July 24, 2012.

4. Don't prescribe interferon- $\beta$ or glatiramer acetate to patients with disability from progressive, nonrelapsing forms of multiple sclerosis.

Interferon- $\beta$ and glatiramer acetate do not prevent the development of permanent disability in progressive forms of multiple sclerosis. These medications increase costs and have frequent side effects that may adversely affect quality of life.

Sources: Rice GP, Incorvaia B, Munari L, et al. Interferon in relapsing-remitting multiple sclerosis. Cochrane Database Syst Rev 2001;4:CD002002. La Mantia L, Munari LM, Lovati R. Glatiramer acetate for multiple sclerosis. Cochrane Database Syst Rev 2010;5:CD004678.

La Mantia L, Vacchi L, Di Pietrantonj C, et al. Interferon beta for secondary progressive multiple sclerosis. Cochrane Database Syst Rev 2012;1:CD005181.

Rojas JI, Romano M, Ciapponi A, Patrucco L, Cristiano E. Interferon beta for primary progressive multiple sclerosis. Cochrane Database Syst Rev $2009 ; 1: C D 006643$.

5. Don't recommend carotid endarterectomy for asymptomatic carotid stenosis unless the complication rate is low (<3\%).

Surgery to repair a narrowed carotid artery that has not caused symptoms reduces the possibility of stroke slightly; however, this benefit is only seen in situations with a documented combined surgical and angiographic complication rate of less than $3 \%$.

Sources: Moore WS, Barnett HJ, Beebe HG, et al. Guidelines for carotid endarterectomy: a multidisciplinary consensus statement from the ad hoc committee, American Heart Association. Stroke 1995;26:188-201.

Chaturvedi S, Bruno A, Feasby T, et al.; Therapeutics and Technology Subcommittee of the American Academy of Neurology. Carotid endarterectomy: an evidencebased review: report of the Therapeutics and Technology Assessment Subcommittee of the American Academy of Neurology. Neurology 2005;65:794-801.

Relapse frequency diminishes over time in patients with relapsing-onset MS, particularly when they enter the secondary progressive phase of the disease. Superimposed relapses in progressive forms of MS do not significantly influence the progression of irreversible disability. ${ }^{30}$ Glatiramer acetate has not been shown to slow even short-term disability progression in RRMS or PPMS. ${ }^{26,31,32}$ While no randomized, controlled trials have been conducted in SPMS, it is logical to extend the findings from the RRMS and PPMS trials. Interferon- $\beta$ and glatiramer acetate are self-injection medications that are frequently poorly tolerated. ${ }^{25,26,28}$ Interferon- $\beta$ often causes worsening of underlying spasticity, flu-like symptoms, injection site reactions, and, less often, depression. ${ }^{25,29}$ Glatiramer acetate often causes injection site reactions, transient flushing, chest tightness, sweating, palpitations, anxiety or a combination of these symptoms. ${ }^{26}$ Both interferon- $\beta$ and glatiramer acetate are very expensive and can place a financial burden on patients and their families. Prescribing these medications to patients with disability from progressive MS who have not had recent relapses increases cost without adding benefit and frequently causes side effects that may adversely affect the patient's quality of life.

Recommendation: Don't recommend CEA for asymptomatic carotid stenosis unless the complication rate is low $(<3 \%)$. Based on studies reporting an upfront surgical complication rate ranging from $2.3 \%{ }^{33}$ to $3.1 \%{ }^{34}$ among patients undergoing CEA for asymptomatic stenosis of $>60 \%$, and an absolute risk reduction for stroke or death of roughly $5 \%$ to $6 \%$ in the surgical group at 5 years, several medical specialty societies ${ }^{35-38}$ have recommended that surgery for asymptomatic patients be reserved for those with a perioperative complication risk of $<3 \%$ and a life expectancy of greater than 3 to 5 years. Although recent studies have reported lower stroke rates with improvements in both surgical ${ }^{36}$ and medical management, ${ }^{39}$ no recent randomized trials have compared these treatments. Therefore, the most recent American Heart Association guidelines ${ }^{35}$ state that it is "reasonable" to perform CEA for asymptomatic patients with $>70 \%$ stenosis if the surgical complication rate is "low." Reported complication rates vary widely by location ${ }^{40}$ and are dependent on how complications are tracked. ${ }^{\text {e1 }}$ Despite calls for rigorous monitoring 
15 years ago, ${ }^{\mathrm{e} 2}$ most patients will likely need to rely on the surgeon's self-reported rates.

DISCUSSION The AAN's Top Five Recommendations were designed to meet the principal objective of the Choosing Wisely campaign-reducing wasteful health care spending. The AAN has not yet determined its exact strategy for Choosing Wisely going forward, although it does expect to produce another Top Five list within the next 2 years.

The AAN's Top Five Recommendations encompass different types of wasteful spending over which neurologists have control. These include non-evidence-based practices that cause more harm than good and thereby incur additional health care expenditures (opiates for migraines and CEA for asymptomatic stenosis); procedures that are done primarily for reimbursement rather than medical necessity (EEGs for headaches and carotid ultrasound for syncope); and prescribing extremely expensive medications that are ineffective (interferon- $\beta$ and glatiramer acetate for progressive, nonrelapsing forms of MS).

Although price estimates are available $(\sim \$ 300$ per routine EEG; $\sim \$ 250$ per carotid Doppler; $\$ 15,000$ per uncomplicated CEA; more than $\$ 40,000 /$ person/ year for interferon- $\beta$ or glatiramer acetate; and $\$ 7,540$ additional cost to employers for medication overuse headache/person/year), ${ }^{\mathrm{e} 3}$ precise estimates of how often these unnecessary tests/procedures/medications are performed or prescribed in the United States are limited. Based on internal Kaiser Permanente estimates, $10 \%$ to $15 \%$ of patients with MS have progressive, nonrelapsing disease and are treated with one of these medications. Generalized to the $\sim 400,000$ Americans with MS, reducing this practice could result in potential savings of $\$ 1.6$ to $\$ 2.4$ billion annually. Reducing the estimated $1.4 \%$ prevalence of medication overuse headache ${ }^{\mathrm{e} 4}$ by $50 \%$ could save approximately $\$ 15$ billion annually in health care costs and lost productivity. ${ }^{\mathrm{e} 3}$ However, these estimates are not precise. An important part of the Choosing Wisely implementation process will be to conduct pre- and post-Choosing Wisely analyses across a variety of delivery systems to obtain more precise information and measure the potential for cost savings.

The first cohort of Choosing Wisely societies made an important impact on the landscape of high-value medicine. By participating in the second cohort, the AAN intends to have a similar impact. According to correspondence with Consumer Reports, more than 57 million people have learned about Choosing Wisely and read the first cohort's Top Five Recommendations. There have been several publications in major medical journals about the Choosing Wisely recommendations and the campaign has garnered significant national media attention. ${ }^{\text {es }}$
The AAN's involvement in Choosing Wisely does not end with the publication of its Top Five Recommendations. There will be future opportunities for the AAN to update the current list and develop additional neurologic recommendations. An important goal will be helping physicians communicate with their patients. This is particularly true for identifying alternatives for migraines, which in some instances may be preventive medications such as topiramate or nortriptyline or, in acute settings, dihydroergotamine. For patients with progressive, nonrelapsing MS, no disease-modifying alternatives have demonstrated unequivocal efficacy. However, optimizing symptomatic treatments for underlying fatigue, depression, pain, and bladder dysfunction can improve functional status and quality of life and is often overlooked in these patients.

It is also important to note the limitations of the Choosing Wisely campaign. There are no studies that detail how much wasteful spending and patient harm can be prevented by following the Choosing Wisely recommendations. Ideally, recommendations would be chosen using a more scientific approach that incorporates this type of information. Additionally, for some suggestions by AAN members, there are simply not enough studies to support or refute the practice. The neurology literature is also lacking in other basic health services studies such as what drives these nonevidence-based practices in the first place. This makes it difficult to discern whether these recommendations will have any impact on reducing wasteful health care spending or could have unintended consequences such as changing the cited indication for ordering the tests/medications/procedures. Physician implementation of the recommendations will certainly be a challenge. The AAN's Choosing Wisely process could be improved by higher levels of physician participation in the recommendation submission phase.

Moving forward, the AAN's goal is to develop successful implementation strategies for its first Top Five list and to obtain accurate estimates of how much wasteful spending and patient harm can be prevented if these or future recommendations are followed. Approaches to develop successful implementation strategies include comparative systems studies to identify factors that dictate when wasteful spending practices are more or less likely and studies that identify barriers and potential solutions to these and other wasteful spending practices. Measuring the impact of these recommendations on health care expenditures will not only gauge the success or failure of different implementation strategies but will also help improve the selection process for future lists. The AAN can facilitate many of these efforts by organizing physician and patient focus groups, helping investigators identify sources of comparative systems data, and developing interactive modules for health care providers to learn 
how to communicate effectively with patients to promote best care practices and value-based medicine.

\section{AUTHOR CONTRIBUTIONS}

Annette Langer-Gould: drafting/revising the manuscript, analysis or interpretation of data. Wayne Anderson: drafting/revising the manuscript, analysis or interpretation of data. Melissa Armstrong: drafting/ revising the manuscript, analysis or interpretation of data. Adam Cohen: drafting/revising the manuscript, analysis or interpretation of data, acquisition of data. Matthew Eccher: drafting/revising the manuscript, analysis or interpretation of data, acquisition of data. Donald Iverson: study concept or design, analysis or interpretation of data, study supervision. Sonja Potrebic: drafting/revising the manuscript. Amanda Becker: study concept or design. Rod Larson: drafting/revising the manuscript. Alicia Gedan: drafting/revising the manuscript, study concept or design, analysis or interpretation of data. Thomas Getchius: drafting/revising the manuscript, study concept or design, analysis or interpretation of data, acquisition of data, study supervision. Gary Gronseth: drafting/revising the manuscript, study concept or design, analysis or interpretation of data, acquisition of data, statistical analysis.

\section{ACKNOWLEDGMENT}

The authors thank Orly Avitzur, MD, MBA, FAAN (Advisory Role); Jonathan Hosey, MD, FAAN (Chair, AAN Practice Committee); Pushpa Narayanaswami, MBBS, MD, FAAN (Former Working Group member); Julie A. Cox, MFA (Manager, AAN Clinical Practice Publications); and Steven R. Messé, MD, FAAN.

\section{STUDY FUNDING}

No targeted funding reported.

\section{DISCLOSURE}

A.M. Langer-Gould serves as a site PI for 2 clinical trials sponsored by Biogen-Idec and Hoffman LaRoche and a diagnostic assay observational study sponsored by Biogen-Idec. Dr. Langer-Gould was formerly a lecturer at Stanford University and currently is also a Clinical Assistant Professor at the University of Southern California. She currently receives grant support from NIH and the National MS Society. Dr. LangerGould's husband was formerly an Associate Professor at Stanford University and the University of Southern California. Dr. Langer-Gould's husband was formally a VA employee and currently receives grant support from NIH and NCI. W.E. Anderson serves on the following advisory boards: Depomed, Insys Therapeutics, and Teva. Dr. Anderson receives funding for travel to meetings where he is invited to speak. Dr. Anderson serves as an advisory member of the Online Team of the American Headache Society. Dr. Anderson receives honoraria from a speaker's bureau for Teva, Insys Therapeutics, Pfizer, and Depomed. M.J. Armstrong serves on the Level of Evidence editorial board for $\mathrm{Neu}$ rology. Dr. Armstrong received fellowship support as an Edmond J. Safra Fellow at the Toronto Western Hospital Morton and Gloria Shulman Movement Disorders Clinic and the Edmond J. Safra Program in Parkinson's Disease in the last 24 months and receives research funding from Abbott as a study subinvestigator. A.B. Cohen receives royalties from Borm Bruckmeier Publishing, LLC, for neurology-related pocket cards and electronic applications. Dr. Cohen has received research support from the Center for Integration of Medicine and Innovative Technology. M.A. Eccher has nothing to disclose. D.J. Iverson serves as a NeuroPI editor and is also currently serving on Neurology Today's editorial board. Dr. Iverson is a member of Acorda Therapeutics' speaker's bureau. S.B. Potrebic receives honoraria for serving on the American Academy of Neurology Residency In-service Training Exam (RITE) workgroup. Dr. Potrebic has received internal Kaiser funding for biostatistician support for "Safety of Headache Medications in the Elderly." A. Becker is an employee of the American Academy of Neurology and has nothing to disclose. R. Larson is an employee of the American Academy of Neurology and has nothing to disclose. A. Gedan is an employee of the American Academy of Neurology and has nothing to disclose. T. Getchius is an employee of the American Academy of Neurology. Mr. Getchius's spouse is employed by Cigna Health Management. G.S. Gronseth serves on the
Neurology Now editorial advisory board and was a member of Boehringer Ingelheim speaker's bureau until December 2011. Dr. Gronseth receives compensation from the American Academy of Neurology for serving as the Evidence-based Medicine Methodologist. Go to Neurology.org for full disclosures.

Received October 11, 2012. Accepted in final form January 29, 2013.

\section{REFERENCES}

1. Alzheimer's Association. 2012 Alzheimer's disease facts and figures. Alzheimers Dement 2012;8:131-168.

2. Heidenreich PA, Trogdon JG, Khavjou OA, et al; American Heart Association Advocacy Coordinating Committee; Stroke Council; Council on Cardiovascular Radiology and Intervention; Council on Clinical Cardiology; Council on Epidemiology and Prevention; Council on Arteriosclerosis; Thrombosis and Vascular Biology; Council on Cardiopulmonary; Critical Care; Perioperative and Resuscitation; Council on Cardiovascular Nursing; Council on the Kidney in Cardiovascular Disease; Council on Cardiovascular Surgery and Anesthesia, and Interdisciplinary Council on Quality of Care and Outcomes Research. Forecasting the future of cardiovascular disease in the United States: a policy statement from the American Heart Association. Circulation 2011;123:933-944.

3. National Institutes of Health. American Recovery and Reinvestment Act Report: ARRA investments in Parkinson's disease. Available at: http://www.ninds.nih.gov/ recovery/investment-reports.html. Accessed July 11, 2012.

4. Centers for Medicare \& Medicaid Services. National health care expenditure projections 2011-2021. Available at: http://www.cms.gov/Research-Statistics-Data-and-Systems/ Statistics-Trends-and-Reports/NationalHealthExpendData/ Downloads/Proj2011PDF.pdf. Accessed July 11, 2012.

5. Martin AB, Lassman D, Washington B, Catlin A; The National Health Expenditure Accounts Team. Growth in US health spending remained slow in 2010; health share of gross domestic product was unchanged from 2009. Health Aff 2012;31:208-219.

6. Institute of Medicine. Best care at lower cost: the path to continuously learning health care in America. The National Academies Press; 2012. Available at: http://www.nap.edu/ catalog.php?record_id=13444. Accessed July 11, 2012.

7. Health Care Costs: A Primer. Key Information On Health Care Costs and Their Impact. Washington, DC: Kaiser Family Foundation; 2012.

8. American Board of Internal Medicine Foundation. Choosing Wisely. Available at: http://www.abimfoundation.org/ Initiatives/Choosing-Wisely.aspx. Accessed September 1, 2012.

9. American Academy of Neurology. Clinical Practice Guideline Process Manual, 2011 ed. St. Paul: The American Academy of Neurology; 2011.

10. Lipton RB, Diamond S, Reed M, Diamond ML, Steward WF. Migraine diagnosis and treatment: results from the American Migraine Study II. Headache 2001;41:638-645.

11. Gronseth GS, Greenberg MK. The utility of the electroencephalogram in the evaluation of patients presenting with headache: a review of the literature. Neurology 1995;45:1263-1267.

12. Silberstein SD. Practice parameter: evidence-based guidelines for migraine headache (an evidence-based review): report of the Quality Standards Subcommittee of the American Academy of Neurology. Neurology 2000;55:754-762.

13. Ganzeboom KS, Mairuhu G, Reitsma J, Linzer M, Wieling W, van Dijk N. Lifetime cumulative incidence of syncope in the general population: a study of 549 
Dutch subjects aged 35-60 years. J Cardiovasc Electrophysiol 2006;17:1172-1176.

14. Sclafani JJ, My J, Zacher LL, Eckart RE. Intensive education on evidence-based evaluation of syncope increases sudden death risk stratification but fails to reduce use of neuroimaging. Arch Intern Med 2010;170:1150-1154.

15. Moya A, Sutton R, Ammirati F, et al; Task Force for the Diagnosis and Management of Syncope; European Society of Cardiology (ESC); European Heart Rhythm Association (EHRA); Heart Failure Association (HFA); Heart Rhythm Society (HRS). Guidelines for the diagnosis and management of syncope (version 2009). Eur Heart J 2009; 30:2631-2671.

16. Mendu ML, McAvay G, Lampert R, Stoehr J, Tinetti ME. Yield of diagnostic tests in evaluating syncopal episodes in older patients. Arch Intern Med 2009;169:1299-1305.

17. Evers S, Afra J, Frese A, et al; European Federation of Neurological Societies. EFNS guideline on the drug treatment of migraine: revised report of an EFNS task force. Eur J Neurol 2009;16:968-981.

18. Institute for Clinical Systems Improvement. Health care guideline: diagnosis and treatment of headache, 10th ed. Published January 2011. Available at: https://www.icsi.org/_asset/jhzzv6/ Headache-Interactive0111.pdf. Accessed July 24, 2012.

19. Kelley NE, Tepper DE. Rescue therapy for acute migraine, part 1: triptans, dihydroergotamine, and magnesium. Headache 2012;52:114-128.

20. Kelley NE, Tepper DE. Rescue therapy for acute migraine, part 2: neuroleptics, antihistamines, and others. Headache 2012;52:292-306.

21. Kelley NE, Tepper DE. Rescue therapy for acute migraine, part 3: opioids, NSAIDs, steroids, and post-discharge medications. Headache 2012;52;467-482.

22. Bigal ME, Lipton RB. Excessive acute migraine medication use and migraine progression. Neurology 2008;71:1821-1828.

23. Linde M, Gustavsson A, Stovner LJ, et al. The cost of headache disorders in Europe: the Eurolight project. Eur J Neurol 2012;19:703-711.

24. Stokes M, Becker WJ, Lipton RB, et al. Cost of health care among patients with chronic and episodic migraine in Canada and the USA: results from the International Burden of Migraine Study (IBMS). Headache 2011;51:1058-1077.

25. Rice GP, Incorvaia B, Munari L, et al. Interferon in relapsing-remitting multiple sclerosis. Cochrane Database Syst Rev 2001;4:CD002002.

26. La Mantia L, Munari LM, Lovati R. Glatiramer acetate for multiple sclerosis. Cochrane Database Syst Rev 2010;5: CD004678.

27. O'Connor P, Filippi M, Amason B, et al; BEYOND Study Group. 250 microg or 500 microg interferon beta- $1 \mathrm{~b}$ versus $20 \mathrm{mg}$ glatiramer acetate in relapsing-remitting multiple sclerosis: a prospective, randomised, multicentre study. Lancet Neurol 2009;8:889-897.

28. La Mantia L, Vacchi L, Di Pietrantonj C, et al. Interferon beta for secondary progressive multiple sclerosis. Cochrane Database Syst Rev 2012;1:CD005181.
29. Rojas JI, Romano M, Ciapponi A, Patrucco L, Cristiano E. Interferon beta for primary progressive multiple sclerosis. Cochrane Database Syst Rev 2009;1:CD006643.

30. Confavreux C, Vukusic S, Moreau T, Adeleine P. Relapses and progression of disability in multiple sclerosis. $\mathrm{N}$ Engl J Med 2000;343:1430-1438.

31. Wolinksy JS, Narayana PA, O'Connor P, et al; PROMiSe Trial Study Group. Glatiramer acetate in primary progressive multiple sclerosis: results of a multinational, multicenter, double-blind, placebo-controlled trial. Ann Neurol 2007;61: 14-24.

32. Fox RJ, Miller DH, Phillips JT, et al; CONFIRM Study Investigators. Placebo-controlled phase 3 study of oral BG12 or glatiramer in multiple sclerosis. N Engl J Med 2012; 367:1087-1097.

33. Executive committee for the Asymptomatic Carotid Atherosclerosis Study. Endarterectomy for asymptomatic carotid artery stenosis. JAMA 1995;273:1421-1428.

34. Halliday A, Mansfield A, Marro J, et al; MRC Asymptomatic Carotid Surgery Trial (ACST) Collaborative Group. Prevention of disabling and fatal strokes by successful carotid endarterectomy in patients without recent neurological symptoms: randomised controlled trial. Lancet 2004;363:1491-1502.

35. Goldstein LB, Bushnell CD, Adams RJ, et al; American Heart Association Stroke Council; Council on Cardiovascular Nursing; Council on Epidemiology and Prevention; Council for High Blood Pressure Research; Council on Peripheral Vascular Disease, and Interdisciplinary Council on Quality of Care and Outcomes Research. Guidelines for the primary prevention of stroke: a guideline for healthcare professionals from the American Heart Association/ American Stroke Association. Stroke 2011;42:517-584.

36. Brott TG, Hobson RW 2nd, Howard G, et al; CREST Investigators. Stenting versus endarterectomy for treatment of carotid-artery stenosis. N Engl J Med 2010;363: $11-23$.

37. Chaturvedi S, Bruno A, Feasby T, et al; Therapeutics and Technology Subcommittee of the American Academy of Neurology. Carotid endarterectomy: an evidence-based review: report of the Therapeutics and Technology Assessment Subcommittee of the American Academy of Neurology. Neurology 2005;65:794-801.

38. Ricotta JJ, Aburahma A, Ascher E, Eskandari M, Faries P, Lal BK; Society for Vascular Surgery. Updated Society for Vascular Surgery guidelines for management of extracranial carotid disease: executive summary. J Vasc Surg 2011; 54:832-836.

39. Marquardt L, Geraghty OC, Mehta Z, Rothwell PM. Low risk of ipsilateral stroke in patients with asymptomatic carotid stenosis on best medical treatment: a prospective, population-based study. Stroke 2010;41: e11-e17.

40. Kresowik TF, Bratzler DW, Kresowik RA, et al. Multistate improvement in process and outcomes of carotid endarterectomy. J Vasc Surg 2004;39:372-380. 


\section{Neurology}

The American Academy of Neurology's Top Five Choosing Wisely recommendations Annette M. Langer-Gould, Wayne E. Anderson, Melissa J. Armstrong, et al. Neurology 2013;81;1004-1011 Published Online before print February 20, 2013

DOI 10.1212/WNL.0b013e31828aab14

This information is current as of February 20, 2013

\section{Updated Information \&} Services

Supplementary Material

\section{References}

Citations

Subspecialty Collections

Permissions \& Licensing

Reprints including high resolution figures, can be found at: http://n.neurology.org/content/81/11/1004.full

Supplementary material can be found at: http://n.neurology.org/content/suppl/2013/02/21/WNL.0b013e31828aa b14.DC1

http://n.neurology.org/content/suppl/2013/04/12/WNL.0b013e31828aa b14.DC2

http://n.neurology.org/content/suppl/2013/09/08/WNL.0b013e31828aa b14.DC3

This article cites 29 articles, 8 of which you can access for free at: http://n.neurology.org/content/81/11/1004.full\#ref-list-1

This article has been cited by 6 HighWire-hosted articles: http://n.neurology.org/content/81/11/1004.full\#\#otherarticles

This article, along with others on similar topics, appears in the following collection(s):

All Headache

http://n.neurology.org/cgi/collection/all_headache

Multiple sclerosis

http://n.neurology.org/cgi/collection/multiple_sclerosis

Information about reproducing this article in parts (figures,tables) or in its entirety can be found online at:

http://www.neurology.org/about/about_the_journal\#permissions

Information about ordering reprints can be found online:

http://n.neurology.org/subscribers/advertise

Neurology ${ }^{\circledR}$ is the official journal of the American Academy of Neurology. Published continuously since 1951, it is now a weekly with 48 issues per year. Copyright () 2013 American Academy of Neurology. All rights reserved. Print ISSN: 0028-3878. Online ISSN: 1526-632X.

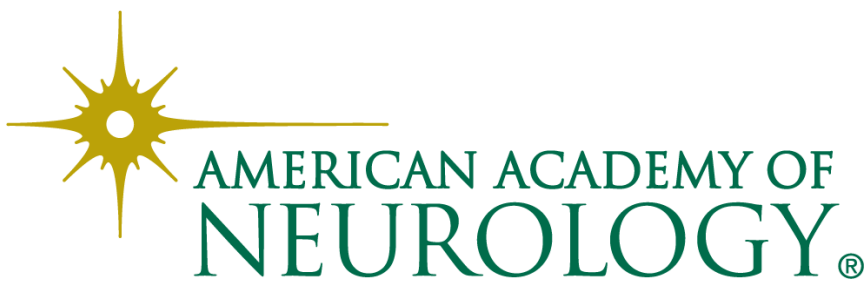

